\title{
Improving Health and Building Human Capital Through an Effective Primary Care System
}

\author{
Albert Lee, Andrew Kiyu, Helia Molina Milman, \\ and Jorge Jimenez
}

\begin{abstract}
To improve population health, one must put emphasis on reducing health inequities and enhancing health protection and disease prevention, and early diagnosis and treatment of diseases by tackling the determinants of health at the downstream, midstream, and upstream levels. There is strong theoretical and empirical evidence for the association between strong national primary care systems and improved health indicators. The setting approach to promote health such as healthy schools, healthy cities also aims to address the determinants of health and build the capacity of individuals, families, and communities to create strong human and social capitals. The notion of human and social capitals begins to offer explanations why certain communities are unable to achieve better health than other communities with similar demography. In this paper, a review of studies conducted in different countries illustrate how a well-developed primary health care system would reduce all causes of mortalities, improve health status, reduce hospitalization, and be cost saving despite a disparity in socioeconomic conditions. The intervention strategy recommended in this paper is developing a model of comprehensive primary health care system by joining up different settings integrating the efforts of different parties within and outside the health sector. Different components of primary health care team would then work more closely with individuals and families and different healthy settings. This synergistic effect would help to strengthen human and social capital development. The model can then combine the efforts of upstream, midstream, and downstream approaches to improve population health and reduce health inequity. Otherwise, health would easily be jeopardized as a result of rapid urbanization.
\end{abstract}

KEYWORDS Health improvement, Human capital, Primary health care.

\section{NEW DIMENSIONS OF HEALTH PROMOTION TO MEET THE CHALLENGES OF DISEASE PREVENTION: IMPORTANCE OF A GOOD PRIMARY HEALTH CARE SYSTEM}

Noncommunicable diseases (NCD) such as cardiovascular disease, diabetes, obesity cancer, and respiratory diseases account for $59 \%$ of the 33 million deaths annually

Lee is with the Centre for Health Education and Health Promotion and Family Medicine Unit of Department of Community and Family Medicine, The Chinese University of Hong Kong, Shatin, Hong Kong; with the Global Programme of Health Promotion Effectiveness of International Union for Health Promotion and Education; and with the Chairman of Award Committee of Alliance for Healthy Cities; Kiyu is with the Sarawak Health, Sarawak, Malaysia; Milman and Jimenez are with the Pontifica Universidad Catolica de Chile, Santiago, Chile.

Correspondence: Albert Lee, Department of Community and Family Medicine, The Chinese University of Hong Kong, 4th Floor, School of Public Health, Prince of Wales Hospital, Shatin, New Territory, Hong Kong. (E-mail: alee@cuhk.edu.hk) 
and $45.9 \%$ of the global burden of disease. ${ }^{1}$ Fifty percent of premature deaths are related to risky health behaviors, and $70 \%$ of disease burdens and costs are due to those risky behaviors. ${ }^{1}$ In a Lancet article, the researchers concluded that abnormal lipids, smoking, hypertension, diabetes, abdominal obesity, psychosocial factors, consumption of fruits, vegetables, and alcohol, and lack of regular physical activity accounted for most of the risk of myocardial infarction worldwide in both sexes and at all ages in all regions. ${ }^{2}$ Prevention is possible when sustained actions are directed both at individuals and families and the broader social, economic, and cultural determinants of NCD. ${ }^{3,4}$ In many urbanized areas, priority health-risk behaviors are often established during youth and extend to adulthood. It is important to have wider dimensions to meet the new challenges rather than by just focusing on downstream (managing health and illness) and midstream (minimization of health risk behaviors) approaches. One needs to take an upstream approach to improve the conditions for health.

The Declaration of Alma Ata urged: "Primary care is essential health care based on practical, scientifically sound and socially acceptable methods and technology made universally accessible to individuals and families in the community through their full participation and at a cost that the community and country can afford to maintain at every stage of their development... ...It is the first level of contact with individuals, the family and community with the national health system bringing health care as close as possible to where people live and work and constitute the first element of a continuing process (International Conference on Primary Health Care, 1978:6)." Primary health care also includes follow up activities to promote community health and to protect members of the community from harm, illnesses, and injuries. The United Nations Department of Economics and Social Affairs (UNDESA) has reported deepening and persistent inequalities worldwide throughout the past decade as result of major gap; in health, education, the workforce, and political participation. 5 Two main areas have emerged as immediate responses: providing access to basic services for the world's poor and building cohesiveness of the community. Research findings have demonstrated that the greater the gap between the rich and poor, the worse the health status of citizens. ${ }^{6-8}$

The UNDESA researchers have tried to explain that the gap is due to unequal access to skill development rather than the income. The notion of social justice needs to infiltrate all primary care activities, and equitable access should supersede individual needs. ${ }^{9}$

Health promotion involves the population in the context of their everyday life combining diverse, but complimentary approaches, including education, communication, organizational changes, community development, fiscal measures, legislation, and local actions leading to healthy public policy. It should reach people through the sectors where they live and meet and set an approach for health such as healthy schools and healthy cities, for example. The work of Sir Michael Marmot's group reports a number of persistent inequities, but there have been some reductions in the gap between the wealthy and poor particularly in promoting health care access for disadvantaged populations. ${ }^{10}$ The group has demonstrated positive outcomes from healthy school programs and other community- and setting-based initiatives, such as provision of services for the hard to reach groups and housing improvement.

For health improvement of the population based on the model of human ecosystem by Hancock and Perkin (Figure 1), interventions need to act at and across different layers and different levels. Both primary health care and setting 


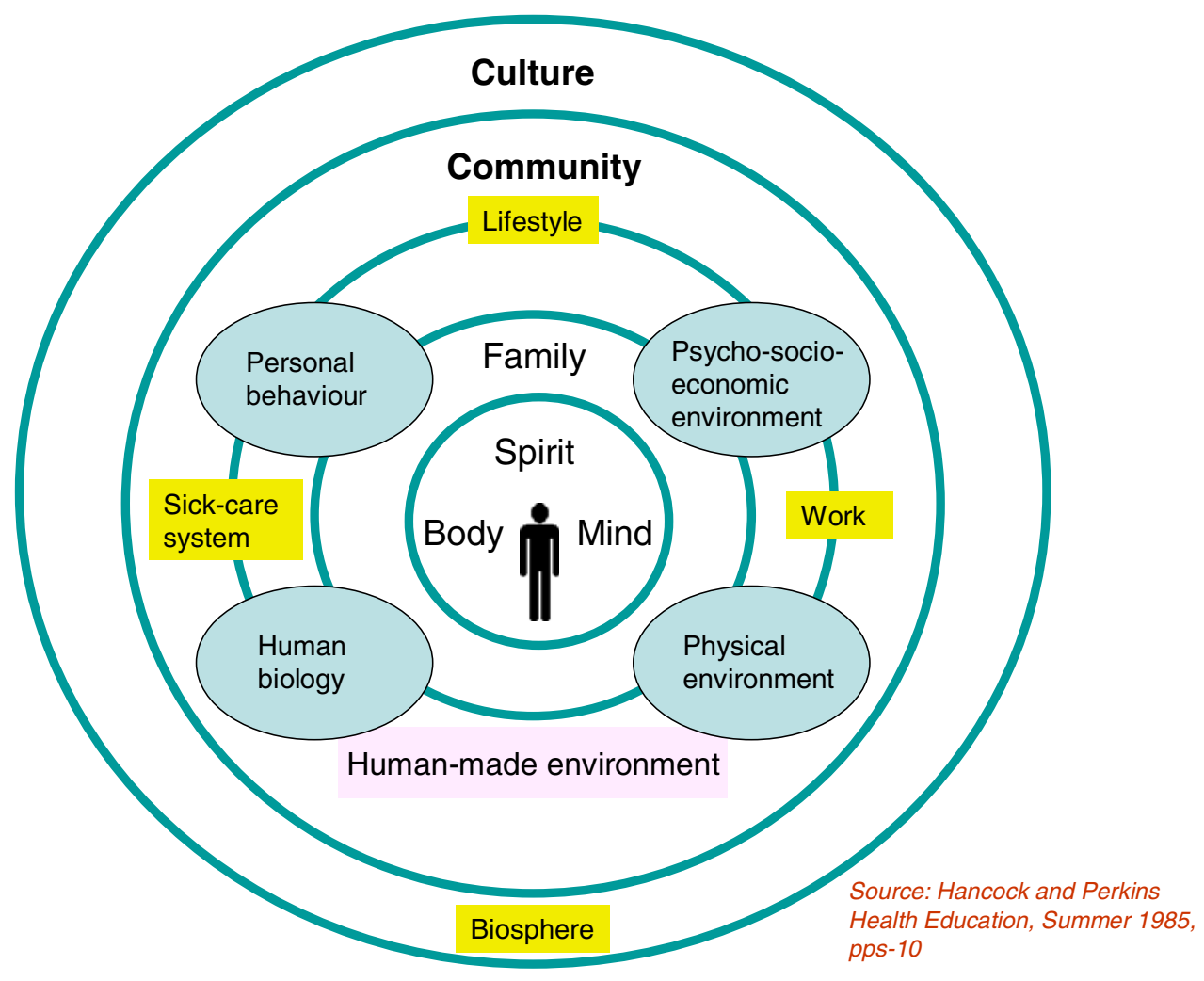

FIGURE 1. Mandala of health: a model of the human ecosystem.

approaches address the determinants of health at both macro- and micro-level. By strengthening community capacity and leadership in primary care, the human capital can be further developed to meet the health challenges of this century.

\section{HUMAN AND SOCIAL CAPITALS ARE KEY CAPITALS IN BUILDING A HEALTHY AND WEALTHY SOCIETY}

“A nation's health is a nation's wealth." Wealth is not just an economic capital, but includes three other forms of capital: social, natural, and human. A healthy community has high levels of social, ecological, human, and economic "capitals"; the combination of which is regarded as "community capital". 4

Human capital consists of healthy, well-educated, skilled, innovative, and creative people who are engaged in their communities and participate in governance.

Social capital constitutes the "glue" that holds communities together formally (social development program) and informally as a social network. It also includes investment in social development so that citizens would have equitable access to basic resources to maintain good health.

Natural capital includes high environmental quality, healthy ecosystems, sustainable resources, nature conservation, and biodiversity.

Economic capital refers to the level of prosperity that we need.

World Bank acknowledged not only the existence but the importance of these four forms of capital as set out in its research report. ${ }^{11}$ It was estimated that $20 \%$ of 
the world's total wealth was found in natural capital, another $20 \%$ in economic capital and the remaining $60 \%$ in combination of social and human capital.

The concept of social capital can be seen as a possible explanation why some communities are prosperous, law-abiding, and healthy, while other communities are not. Social capital has been defined as those features of social organization-such as the extent of interpersonal trust between citizens, norms of reciprocity, and density of civic. ${ }^{12,13}$ It constitutes the "glue" that holds the community together, and it has been shown that states with low social capital had higher proportions of residents reporting poor or fair health. ${ }^{13}$

Social capital may influence the health behaviors by promoting more rapid diffusion of health information, increasing the likelihood that healthy norms of behavior are adopted, and exerting social control over deviant health-related behavior. Innovative behaviors diffuse much more rapidly in communities that are cohesive and whose members know and trust one another. ${ }^{13}$

Human capital can be regarded as the sum of the capacities of all individuals in the community-their level of intelligence, education, creativity, and innovativeness, health and well-being, capacity for empathy, and caring. Human beings are the central focus of development and the ultimate purpose of communities, government and societies, so building human capital can lead to health improvement. ${ }^{14}$

\section{EFFECTIVE PRIMARY CARE DEVELOPMENT TO BUILD UP HUMAN CAPITAL AND IMPROVE HEALTH OF THE POPULATION}

There is strong theoretical and empirical evidence for the association between strong national primary care systems and improved health indicators. ${ }^{15-17}$ Studies have also shown the promotion of primary care service as a more feasible and less expensive strategy for combating mortality. ${ }^{18-24}$ This paper reports the evidence of how a well-developed primary health care system would reduce all causes of mortalities, lead to better health status, and uptake of preventive services, and reduce hospitalization. A model can be developed to join up different settings for health promotion by combining the efforts of different parties within and outside the health sector and integrate with different components of the primary health care team that work closely with individuals and families to improve population health.

\section{DEVELOPMENT OF A GOOD PRIMARY HEALTH CARE SYSTEM IS A MORE SUSTAINABLE SOLUTION TO IMPROVE HEALTH}

There has been substantial literature suggesting a significant association between income inequality and mortality, ${ }^{25-29}$ and while the pathways are still unknown, hypotheses include psychosocial and material pathways. ${ }^{30}$ Other investigators have postulated that the political and policy context is itself a precursor to health inequalities. ${ }^{13,31}$ Primary care addresses the most common problems in the community. It integrates care where there is more than one health problem and deals with the context in which illness exists and influences the responses of people to their health problems. It organizes and rationalizes the deployment of health resources, basic and specialized, directed at promoting, maintaining, and improving health. ${ }^{32}$ If the independent effect of primary care on reduced mortality would be demonstrated, it represents a specific mechanism for addressing at least some of the health impact of growing social inequalities. 


\section{Case Studies Reflecting the Independent Effect of Primary Health Care and Health Improvement}

Shi et al. has designed a set of nested models to examine the independent effect of primary care and income inequality on mortality and the extent to which the addition of primary care to the statistical model attenuates the association between income inequality and mortality. ${ }^{33}$ By using 11 years of data, they are able to examine the relationship among the variables of interest in more than one period, thus, improving the robustness of their findings to changes over time.

A set of nested models was designed to examine the independent effect of primary care and income inequality on mortality and the extent to which the addition of primary care to the statistical model attenuates the association between income inequality and mortality. In model 1 , only income inequality was used as a predictor of mortality. In model 2, mortality is predicted by both income inequality and sociodemographic characteristics of the population. Model 3 includes primary care along with the other covariates included in model 2. Both primary care (inversely) and income inequality (positively) are significantly associated with total mortality $(p<0.01$ for primary care and $p<0.05$ for income inequality). Among sociodemographic indicators, blacks $(p<0.01)$ and unemployment $(p<0.05)$ are significantly and positively related to mortality; education $(p<0.01)$ is significantly and inversely related to mortality. The inclusion of sociodemographics, particularly percentage of black, reduces the regression coefficient of income inequality to insignificance. In model 3, primary care is independently and inversely associated with mortality. An increase of one primary care doctor per 10,000 population is associated with a reduction of 1.44 deaths per 10,000 population, after taking into account the effects of income inequality and the sociodemographic correlates of mortality.

These findings are also consistent with other research findings that attributes a significant percentage of the increase in life expectancy in the developed world over the past 50 years. ${ }^{34}$ Preventive services and therapeutic intervention were credited with approximately 5 of the 30 years of increase in life expectancy since $1950 .{ }^{35}$ The impact of primary care would be explained by having access to a regular source of primary care leading to improvement of prevention and early detection of chronic diseases. ${ }^{36}$ Primary care makes its contribution to health by providing comprehensive, coordinated, and longitudinal care upon first contact with the health system. Highquality primary care can also lead to more efficient secondary and tertiary care. ${ }^{37}$

Shi et al. shows that in U.S. counties, greater primary care resources are consistently associated with lower rates of all-cause, heart disease, and cancer mortalities even in the presence of income inequality and other health determinants. ${ }^{38}$ Primary care may serve as a more feasible and less expensive strategy for combating mortality and reducing socioeconomic disparities in health compared with either social policy addressing determinants of health or behavioral modifications.

\section{CASE STUDIES ON HEALTH IMPROVEMENT OF PARTICULAR AGE GROUPS OR DISEASES AND HOW LONGITUDINALITY OF PRIMARY CARE LEADS TO HEALTH IMPROVEMENT}

Study by Shi et al. used 11 years of U.S. state level data to examine the impact of primary care on both infant mortality and prevalence of low birth weight. ${ }^{39}$ In multivariate analysis model, an increase of one primary care doctor per 10,000 population was associated with $2.5 \%$ reduction in infant mortality and a $3.2 \%$ reduction of low birth weight on average. Primary care would influence birth 
outcomes by improving maternal health and better management of conditions affecting infants in postnatal period such as identification and treatment of infections, teaching mothers about safe sleeping position, and injury prevention. A range of maternal health problems associated with higher rates of infant mortality such as smoking, alcoholism, substance misuse, and poor nutrition can also be tackled. ${ }^{40}$

Basic primary health care has been a critical instrument of health planners in the Latin American and Caribbean Region (LAC) in the process of reduction of infant mortality. LAC and especially Chile have done very well and have rates of under 25 deaths per 1,000 live births, and infant mortality has two clear phases of decline. ${ }^{24}$ The initial phase is clearly influenced by the essential primary care interventions such as antenatal care, professional care of deliveries, well baby control, immunizations, and common diseases treatment, together with the environmental interventions regarding safe water and sanitation. The primary care network in Chile was progressively developed in the 1950s and 1960s, with visible impact in the mid-1970s. This last impact of social protection network schemes in the midst of an economic crisis was positively evaluated by UNICEF. In 2000, Chile reached a figure of 8.9 infant deaths per 1,000, one of the lowest in the LAC Region.

Another study revealed that rural adolescents without regular source of care were four times less likely to obtain both preventive and illness care. ${ }^{41}$ It was also found that not having the same source of care for preventive care and treatment almost doubled the likelihood of adolescents using emergency services. Lacking a single source of care for both prevention and treatment, adolescents would receive less preventive and problem-focused care. Having a regular source of care and not health insurance was found to be associated with a twofold increase of an adolescent's having received preventive care in the previous 2 years.

A study by Lee et al. found that the prevalence rates of good health and hygiene behaviors and scores in all three main domains of the Children Behavior Checklist (anxious/depressed, somatic complaints, and aggressive behaviours) were higher among those children with family physicians with statistical significance after adjusting for socioeconomic status. ${ }^{42}$ Two international comparisons, with 13 industrialized countries characterized by the strength of their primary care health systems, document the relevance of primary care to effectiveness and efficiency of health services. Primary care-oriented countries (namely, Denmark, Finland, Netherlands, Spain, and United Kingdom) achieve notably better outcomes for health in early childhood: low birth weight ratios, postneonatal mortality, infant mortality, child mortality, ${ }^{16,43}$ and deaths from injury. ${ }^{44}$ The United States ranks near the bottom on all of these measures and is rated the lowest in primary care orientation. ${ }^{16}$ The greater the extent to which a wide range of services provided by primary care practitioners and family orientation of these services is associated with better health outcomes at lower costs. ${ }^{16}$

Depressed patients in primary care centers having a relationship with a particular primary care physician were found to be more likely to have a frank presentation of their depression than patients at centers. In this WHO study of 1,146 patients with a diagnosis of major depression in 15 primary care centers in 14 countries on 5 continents, depressed patients in centers without this relationship were more likely to present themselves with somatic symptoms. ${ }^{45}$

In the United Kingdom, the number of general practitioners per 100,000 population was found to be related to lower in-hospital standardized mortality. ${ }^{20}$ In 
Japan, older people with regular physicians are less likely to be taking many prescribed drugs. ${ }^{21}$ Comparisons of the rate of decline for avoidable mortality in the United States and Canada found that Canada had a more rapid decline than in the United States. The lowest avoidable mortality ratios in Canada were for disease groups in which primary care would be expected to play a major role: asthma, cervical cancer, hypertension and cerebrovascular disease, tuberculosis, and maternal mortality, as opposed to those generally requiring specialist treatment in the hospital (Hodgkin's disease, cholecystitis, and abdominal hernia). ${ }^{22}$ Canada has put more emphasis on primary care, demonstrated by a higher per capita proportion of primary care physicians than in the U.S., and comprehensive health care is freely available at the point of use.

In Spain, a national primary care reform was implemented in stages, with the most deprived areas undergoing the reform first. Within a 10-year period after the reform was started, those areas in which it was first implemented demonstrated the largest decline in mortality rates associated with hypertension. ${ }^{23}$ Hypertensionrelated conditions are known to be responsive to primary care-level interventions. On the contrary, deaths associated with causes that are responsive to specialty care intervention declined, but in no particular pattern relative to the primary care reform.

Healthy Step (HS) by McLearn et al. utilized a partnership of physician and early child development specialist to meet the needs of parents and children in a better way. ${ }^{46}$ It includes enhanced well child care through office visits with physicians and HS specialists, home visits by HS specialists, child development, and family health checkup, written information materials for parents emphasizing disease prevention and health promotion, parent group offering social support and interactive learning opportunities, and linkage to community resources. This approach has narrowed the income gaps in preventive services for children with higher satisfaction, and also their needs are now being met. ${ }^{47}$

\section{PRIMARY HEALTH CARE AND URBANIZATION}

Health care should be available where people live and work. As result of rapid urbanization, the people tend to move away from rural and remote areas to live in urban areas. The rural and remote areas might no longer be included in public health services provision schemes based on cost inefficiency. Mainland China is an example. Since the early 1980s, China has reduced the central government's investment in health care services and many other public health services. From 1978 to 1999, the national health care spending fell from 32 to $15 \%{ }^{48}$ Much of the responsibility for funding health care services are now at local authorities. Revenues would be generated by provision of new drugs, new tests, and technology. ${ }^{49}$ With emerging market-based health care system, the affordability of patients become the main predictor for accessibility to services. Disadvantaged citizens have difficulty in accessing quality health care if they become very ill. They bypass the local doctors to seek help from outpatient clinics of urban hospitals. This would lead to a heavy financial burden on seeking expensive hospital services. It is important to ensure an effective health care safety net.

If the hospital services in China are moving toward market system like the USA, one would consider building up a good system of state-funded primary care to act as a gatekeeper to hospitals and to balance the problem of inequities. The services 
need to be widely accessible to particularly the disadvantaged group, and a universal approach might not fully address the questions of inequity. The setting approach for health promotion ensures that the ethos of the setting and all the activities are mutually supportive and combine synergistically to improve the health of those living or working there. It integrates health promotion into all aspects of the setting including those coming into contact with that setting. This helps to bring those disadvantaged groups into contact with essential primary health care service. It shifts the focus from risk factors to organizational change ensuring sustainability of the system. ${ }^{50}$ Primary health care can serve to bridge the gap between macroand micro-levels pulling the community resources together for efficient use. The "Healthy Setting" movement revitalizes the public health movement, and if this would integrate with the primary health care system, this would synergize the effect of health improvement.

\section{WHAT SHOULD BE THE EFFECTIVE INTERVENTION FOR HEALTH IMPROVEMENT AND BUILDING HUMAN CAPITAL}

Health could not be improved simply by provision of health services focusing on particular diseases or organs. The supply of primary health care services has been shown to be the independent factor associated with positive health outcomes. The benefits of good primary care for socioeconomically disadvantaged people have also been shown. Apart from availability, the primary care services need to be widely accessible particularly to the disadvantaged group, and universal approach might not fully address the questions of inequity. The Healthy Setting approach ensures that the ethos of the setting and all the activities are mutually supportive and combine synergistically to improve health and well-being of those who live or work on receive care there. ${ }^{50}$ It integrates health promotion into all aspects of the setting

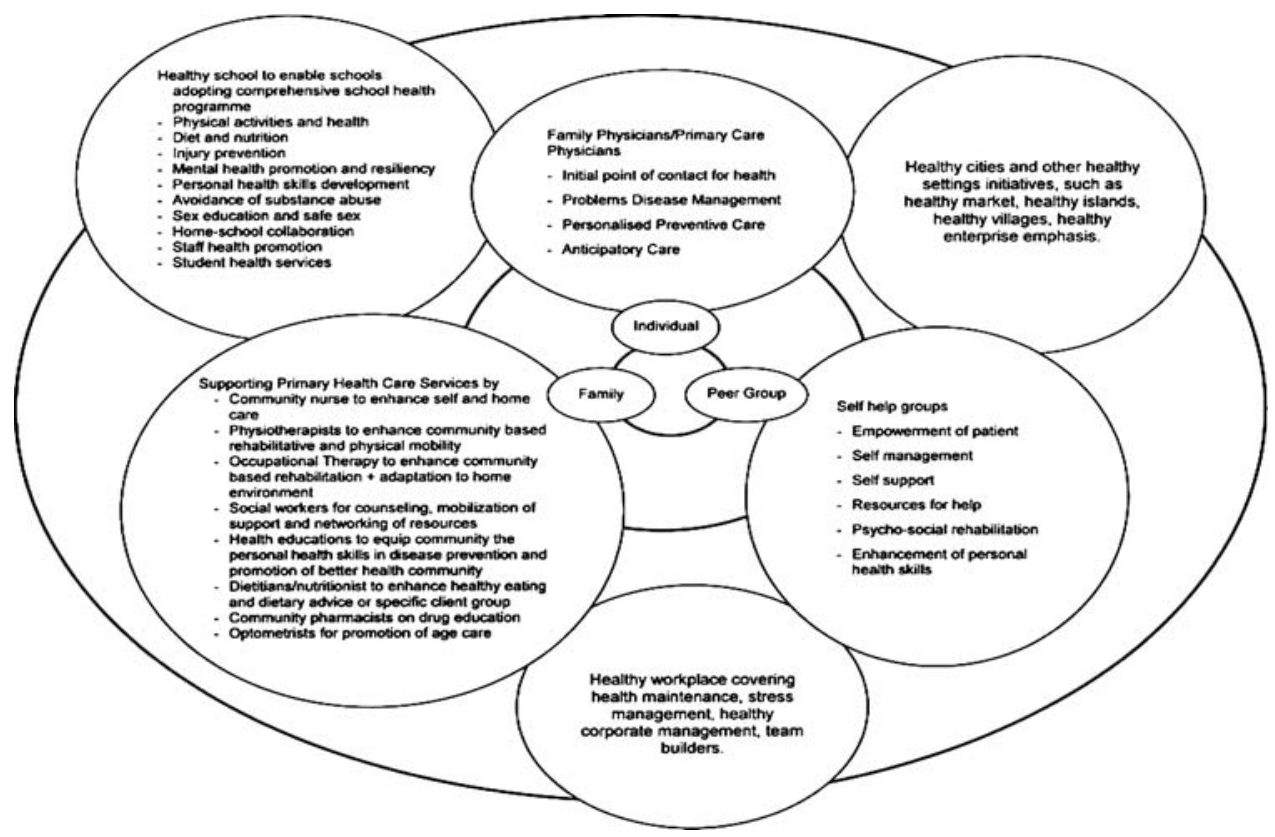

FIGURE 2. Interconnected and comprehensive health improvement model. 
including all those coming into contact with that setting. This will help to bring those disadvantaged groups into contact of essential primary health care service. This shifts away from specific health behavior change towards creating the conditions that are supportive of health and well-being. It shifts the focus from risk factors to organizational change, so sustainability of the system can be ensured. ${ }^{50}$

Figure 2 shows how primary health care and healthy setting can cut across different levels interacting with each other through interconnectedness of individuals, families, and peers, with comprehensive and integrated primary care system and healthy setting approach. Evidence has shown that preventive interventions are best in primary care when they are not related to any one disease or organ system such as being physically active, eating a healthy diet, quitting smoking, and breastfeeding. ${ }^{18,51}$ If individuals are only working on their own, they will face many barriers, as many factors are beyond the control of an individual and even the health care sector. Primary health care services can serve to bridge the gap between macro- and micro-levels and also pull the community resources together for efficient use. The model (Figure 2) would serve as a new model of health improvement and building up of human capitals in meeting the challenges of health as a result of rapid urbanization and globalization.

\section{REFERENCES}

1. WHO. The World Health Report 2002-Reducing risks, promoting Healthy Life. 2002.

2. Yusulf S, Hawkens S, Ounpu S, et al. Effects of potential modifiable risk factors associated with myocardial infarction in 52 countries (the INTERHEART study); casecontrol study. Lancet. 2004;364(9438):937-952.

3. Mant D. Principles of prevention. In: Jones R, Britten N, Culpepper L, Gass DA, et al., eds. Oxford Textbook of Primary Medical. Oxford: CareOxford University Press; 2004:369-372.

4. Hancock T. People partnership and human progress: building community capital. Health Promot Int. 2001;16(3):275-280.

5. United Nations Department of Economic and Social Affairs. Statistic Division. "World and Regional Trends'. Millenium Indicators Data Base; based on data provided by United Nation Children's Fund, World Health Organisation, and Food and Agriculture Organisation of the United Nations. 2005.

6. Raphael D. Letter from Canada: paradigms, politics and principles-an end of the millennium update from the birth place of the Healthy Cities movement. Health Promot Int. 2001;16(1):99-101.

7. Labone R. Health Promotion in the 21st century: celebrating the ordinary. Health Promotion Journal of Australia. 2001;12(2):104-109.

8. Kawachi I, Kennedy B. Income inequality and health: pathways and mechanisms. Health Serv Res. 1999;34:215-227.

9. Murray A. Community Health and Wellness: A Socio-ecological Approach. Australia: Mosby Elsevier; 2007.

10. WHO. Towards a Conceptual Framework for Analysis and Action on the Social Determinants of Health. Commission on Social Determinants of Health discussion paper, 2005.

11. World Bank. Monitoring Environmental Progress (MEP) A Report on work in Progress. Washington DC: World Bank; 1995.

12. Putnam RD. Making Democracy Work. Princeton, NJ: Princeton University Press; 1993.

13. Kawachi I, Kennedy BP, Glass R. Social capital and self-rated health: a contextual analysis. Am J Public Health. 1999;89(9):1187-1193. 
14. Hancock T. Health, human development and the community eco-system: three ecological models. Health Promot Int. 1993;8(1):41-47.

15. Macinko J, Starfield B, Shi L. The contribution of primary care systems to health outcomes within OECD countries, 1970-1998. Health Serv Res. 2003;38:819-853.

16. Starfield B, Shi L. Policy relevant determinants of health: an international perspective. Health Policy. 2002;603:201-218.

17. Starfield B. Is primary care essential? Lancet. 1994;344:1129-1133.

18. Starfield B, Shi L, Macinko J. Contribution of primary care to health systems and health. Milbank Q. 2005;83:457-502.

19. Shi L, Starfield B, Xu J, Politzer R, Regan J. Primary care quality: community health center and health maintenance organization. South Med J. 2003;96:787-795.

20. Jarman B, Gault S, Alves B, et al. Explaining differences in English hospital death rates using routinely collected data. BMJ. 1999;318:1515-1520.

21. Tsuji-Hayashi Y, Fukuhara S, Green J, Kurokawa K. Use of prescribed drugs among older people in Japan: association with not having a regular physician. J Am Geriatr Soc. 1999;47:1425-1429.

22. Manuel DG, Mao Y. Avoidable mortality in the United States and Canada, 1980-1996. Am J Public Health. 2002;92:1481-1484.

23. Villalbi JR, Guarga A, Pasarin MI, et al. An evaluation of the impact of primary care reform on health. Aten Prim. 1999;24:468-474 (in Spanish).

24. Jiménez J, Romero MI. Reducing infant mortality in Chile: success in two phases. Health Aff. 2007;26:2.

25. Lochner K, Pamuk E, Makuc D, Kennedy B, Kawachi I. State-level income inequality and individual mortality risk: a prospective, multilevel study. Am J Public Health. 2001;91:385-391.

26. McLaughlin DK, Stokes CS. Income inequality and mortality in U.S. counties does minority racial concentration matter? Am J Public Health. 2002;92:99-104.

27. Subramanian SV, Blakely T, Kawachi I. Income inequality as a public health concern where do we stand? Commentary on "Is exposure to income inequality a public health concern?" Health Serv Res. 2003;38:153-167.

28. Lynch JW, Smith GD, Harper S, et al. Is income inequality a determinant of population health? Part I. A systematic review. Milbank Q. 2004;82:5-99.

29. Blakely TA, Lochner K, Kawachi I. Metropolitan area income inequality and self-rated health-a multi-level study. Soc Sci Med. 2002;54:65-77.

30. Wilkinson RG. Unhealthy Societies the Afflictions of Inequality. London: Routledge; 1996.

31. Navarro V, Shi L. The political context of social inequalities and health. Soc Sci Med. 2001;52:481-491.

32. Lee A. Editorial: core skills in family medicine is needed for primary care doctors. Hong Kong Pract. 2006;193-195.

33. Shi L, Macinko J, Starfield B, Politzer R, Xu J. Primary care, race, and mortality in U.S. states. Soc Sci Med. 2005;61:65-75.

34. Bunker JP. Medicine Matters After All Measuring the Benefits of Medical Care, a Healthy Lifestyle and a Just Social Environment. London, UK: Nuffield Trust; 2001.

35. Bunker JP, Frazier HS, Mosteller F. The role of medical care in determining health creating an inventory of benefits. In: Amick BC III, Levine S, Tarlov AR, Walsh DC, eds. Society and Health. New York, NY: Oxford University Press; 1995.

36. Shea D, Misra MH, Ehrlich L, et al. Predisposing factors for severe, uncontrolled hypertension in an inner-city minority population. N Engl J Med. 1992;327:776-781.

37. Casanova C, Colomer C, Starfield B. Pediatric hospitalization due to ambulatory caresensitive conditions in Valencia (Spain). Int J Qual Health Care. 1996:8(1):51-59.

38. Shi LY, Macinko J, Starfield B, et al. Primary care, social inequalities, and all-cause, heart disease, and cancer mortality in U.S. counties, 1990. Am. J. Public Health. 2005;95(4): 674-680. 
39. Shi L, Macinki J, Starfield B, et al. Primary care, infant mortality, and low birth weight in the states of the USA. J Epidemiol Community Health. 2004;58:374-380.

40. Baketeig L, Jacodsen G, Hoffman H, et al. Pre-pregnancy risk factors of small for gestational age birth among parous women in Scandinavia. Acta Obstet Gynecol Scand. 1993;72:273-279.

41. Ryan S, Riley A, Kang M, Starfield B. The effects of regular source of care and health need on medical care use among rural adolescents. Arch Pediatr Adolesc Med. 2001;155(2):184-190.

42. Lee A, Wong J, Lam C, Fung Y, Kan W, Leung P. Children with regular family doctors have better psycho-social health and health behaviours. Aust Fam Physician; 2007 (in press).

43. World Health Organization. The World Health Report 2000. Health Systems: Improving Performance. Geneva, Switzerland: World Health Organization; 2000. Available at: http:// www.who.int/whr2001/2001/archives/2000/en/contents.htm. Accessed May 13, 2003.

44. UNICEF (2003). A league table of child deaths by injury in rich nations. Florence, Italy: United Nations Children's Fund, Innocenti Research Center, Available at: http:// www.unicef-icdc.org/publications/pdf/repcard2e.pdf. Accessed May 13, 2003.

45. Simon GE, VonKorff M, Piccinelli M, Fullerton C, Ormel J. An international study of the relation between somatic symptoms and depression. N Engl J Med. 1999;341:1329-1335.

46. McLearn KT, Zuckerman B, Parker S, Yellowitz M, Kaplan-Sanoff M. Child development and pediatrics for the 21st Century; the Healthy Steps approach. J Urban Health. 1998;75:704-722.

47. McLearn KT, Strobino DM, Minkovitz CS, Marks E, Bishai D, Hou W. Narrowing the income gaps in preventive care for young children; families in healthy steps. J Urban Health. 2003;81(4):556-567.

48. Liu Y. China's public health-care system: facing the challenges. Bull World Health Organ. 2004;82:532-538.

49. Hesketh T, Zhu W. Health in China: the healthcare market. BMJ. 2004;314:1616-1618.

50. Lee A, Cheng F, Fung Y, St Leger L. Can health promoting schools contribute to the better health and well being of young people: Hong Kong experience? J Epidemiol Community. 2006;60:530-536.

51. Shi L, Starfield B. Primary care, income inequality, and self-rated health in the United States: a mixed-level analysis. Int J Health Serv. 2000;30:541-555. 